\title{
Review \\ Deciphering the Complex Molecular Pathogenesis of Myotonic Dystrophy Type 1 through Omics Studies
}

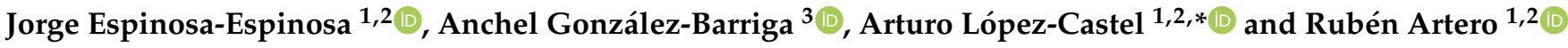 \\ 1 University Research Institute for Biotechnology and Biomedicine (BIOTECMED), Universidad de Valencia, \\ 46100 Valencia, Spain; jorge.espinosa@uv.es (J.E.-E.); ruben.artero@uv.es (R.A.) \\ 2 Translational Genomics Group, Incliva Biomedical Research Institute, 46010 Valencia, Spain \\ 3 Centre de Recherche en Myologie, Inserm, Institut de Myologie, Sorbonne Université, 75013 Paris, France; \\ anchel.gonzalez-barriga@inserm.fr \\ * Correspondence: arlocas@uv.es; Tel.: +34-963543028
}

check for updates

Citation: Espinosa-Espinosa, J. González-Barriga, A.;

López-Castel, A.; Artero, R.

Deciphering the Complex Molecular Pathogenesis of Myotonic Dystrophy Type 1 through Omics Studies. Int. J. Mol. Sci. 2022, 23, 1441. https:// doi.org/10.3390/ijms23031441

Academic Editor: Lubov Timchenko

Received: 31 December 2021

Accepted: 26 January 2022

Published: 27 January 2022

Publisher's Note: MDPI stays neutral with regard to jurisdictional claims in published maps and institutional affiliations.

Copyright: (C) 2022 by the authors. Licensee MDPI, Basel, Switzerland. This article is an open access article distributed under the terms and conditions of the Creative Commons Attribution (CC BY) license (https:// creativecommons.org/licenses/by/ $4.0 /)$
Abstract: Omics studies are crucial to improve our understanding of myotonic dystrophy type 1 (DM1), the most common muscular dystrophy in adults. Employing tissue samples and cell lines derived from patients and animal models, omics approaches have revealed the myriad alterations in gene and microRNA expression, alternative splicing, $3^{\prime}$ polyadenylation, CpG methylation, and proteins levels, among others, that contribute to this complex multisystem disease. In addition, omics characterization of drug candidate treatment experiments provides crucial insight into the degree of therapeutic rescue and off-target effects that can be achieved. Finally, several innovative technologies such as single-cell sequencing and artificial intelligence will have a significant impact on future DM1 research.

Keywords: transcriptomics; proteomics; alternative splicing; alternative polyadenylation; expanded CUG repeats; gene expression; therapies; myotonic dystrophy; RNA-binding proteins; RNA metabolism

\section{Introduction}

Myotonic dystrophy type 1 (DM1), an inherited neuromuscular disease, is the most common type of muscular dystrophy in adults, with a reported prevalence of up to one in every 2100 births $[1,2]$. DM1 is a multisystem disorder with diverse symptoms, including muscle hyperexcitability (myotonia), progressive muscle wasting, cardiac arrhythmias, insulin resistance, gastrointestinal dysfunctions, posterior iridescent cataracts, and neuropsychiatric disturbances [3]. The disease is caused by an expanded trinucleotide (CTG) repeat in the 3-prime untranslated region ( $3^{\prime}$-UTR) of the DM1 protein kinase (DMPK) gene. Disease severity varies with the number of CTG repeats: unaffected individuals carry 5 to 37 triplets, mildly affected persons between 50 and 150, patients with classic DM1 from 100 to 1000, and those with onset at birth can have more than 2000 repeats [4]. The primary molecular mechanism causing this disorder is the toxicity generated by expanded CUG repeats present in the $3^{\prime}$-UTR of mutant $D M P K$ transcripts, which alters the function of various downstream effectors, triggering gene deregulations through alterations in transcription [5], translation [6], gene silencing [7], alternative splicing [8], and polyadenylation [9]. In DM1, the most studied families of RNA-binding proteins (RBPs) affected by mutant DMPK transcript toxicity are the CUGBP-ETR-3-like (CELF) and Muscleblind-like (MBNL) factors, both controlling the inclusion of alternative exons in several transcripts according to tissue and developmental state cues [10]. Currently, there is no cure available to halt or slowdown DM1 progression. Therefore, therapeutic advances are urgently needed since patient medical care is limited to clinical management and symptomatic treatment, such as anti-diabetic or anti-myotonic drugs, rehabilitation therapy, or surgery, which, despite improving the quality of life of the patients, are not definitive treatments against the root causes of the disease [11]. New and promising treatments are being developed to 
suppress or even eliminate the molecular effects of DM1, such as toxic RNA degradation or MBNL expression enhancers [12].

The MBNL family comprises the MBNL1, MBNL2, and MBNL3 RNA metabolism regulators, whose expression levels are tightly regulated by the developmental stage in each tissue. MBNL1 and 2 are broadly expressed, but MBNL1 is the paralog that serves a primary role in most tissues, except for the brain, where MBNL2 is predominantly detected, whereas $M B N L 3$ expression is more restricted and has been related to muscle-cell differentiation inhibition, aging, and regeneration [13-16]. The CELF RBP family comprises six members, divided into two groups according to their expression level. CELF1 and 2 are highly expressed in various tissues, such as skeletal muscle, brain, and heart, constituting the first and most studied group. CELF3-6 are mostly present in neurons, and CELF6 can also be found in kidneys and testes $[17,18]$.

Alternative splicing (AS) is an RNA-processing mechanism that removes sequences (introns) between splicing sites in pre-mRNAs to process mRNAs [19]. It is mediated by the spliceosome and heavily regulated by different sequence motifs, which are recognized by RBPs that can act as repressors or enhancers of each splicing site. This process contributes crucially to proteome diversity by allowing a single gene to code more than one mRNA and potentially have more than one function [20]. Polyadenylation is the last key step in RNA maturation, which involves the cleavage of nascent pre-mRNA $3^{\prime}$-end and addition of a poly(A) tail at the cleavage site, which plays a leading role in the translation efficiency, stability, and localization of mRNAs. If a gene possesses more than one poly(A) site, the difference in usage of those sites is called alternative polyadenylation (APA) [21,22]. In DM1, both AS and APA processes have been reported to be altered and to play an essential role in pathogenesis [9].

Various disease models have been developed to investigate the pathogenic mechanisms associated with DM1. Some of the most commonly used in omics studies are: (1) the $\mathrm{HSA}^{\mathrm{LR}}$ mouse model, a transgenic mouse carrying a genomic fragment of the human skeletal actin (ACTA1) gene with $\sim 250$ CTG repeats in the $3^{\prime}$-UTR, which is expressed in the skeletal muscle only. This model recapitulates RNA toxicity alterations by displaying myopathy, centrally located nuclei in muscle fibers, and AS defects [23]. (2) The DMSXL mouse model is a transgenic line carrying $45 \mathrm{~kb}$ of the human genome from the DM1 locus with $>1000$ CTG repeats. DMSXL mice reproduce key molecular hallmarks of DM1, such as nuclear foci in most tissues (except epithelia), RNA mis-splicing in multiple tissues, and relevant muscle, cardiac, neuron, and glial cell phenotypes [24-26]. Finally, (3) patient-derived immortalized myoblasts (PDIM) with >2000 CTG repeats can be used for in vitro experiments. They show ribonuclear aggregates that colocalize with MBNL1 and splicing defects in key genes such as ATP2A1, BIN1, INSR, LDB3, MBNL1, and TNNT2 [27]. Other less frequently used or recently developed models will be discussed in the corresponding section.

In recent years, new advances in and the widespread application of omics technologies have enabled cost-efficient, high-throughput, in-depth analyses of transcripts, proteins, and other molecules, creating an unprecedented body of knowledge [28] and enabling advances in personalized medicine [29], cancer research [30], and rare diseases [31,32]. Herein, we reviewed the literature on DM1, since the number of omics studies far exceeds those involving Myotonic Dystrophy Type 2 (DM2), focusing particularly on the tools used to elucidate the pathological mechanisms involved, to broaden the scope of our understanding of this complex multisystem disorder.

\section{Omics Studies in DM1}

Transcriptomics is the study of the full range of transcripts at the RNA level of a biological system [33]. Tools such as microarrays, RNA-Sequencing (RNA-Seq), high-throughput sequencing of RNA isolated by crosslinking immunoprecipitation (HITS-Clip), and their corresponding variations, have been extensively used to study transcriptome complexity in DM1. Splice-sensitive microarrays have been employed to identify disease-related splicing 
alterations and describe specific deregulations of isoform expression, while hundreds of target sequences have been established for both MBNL and CELF proteins using HITS-Clip. More recently, RNA-Seq has been used to determine gene expression and splicing changes in various DM1 tissues and disease models. All these studies will be covered in more detail in the following sections. Transcriptomics, however, does not provide reliable information about the fate of a given gene product after translation. Therefore, analysis of the proteome is essential to elucidate the extent of DM1 post-transcriptional dysregulation in each cell type, tissue, developmental stage, or disease condition. In this regard, mass spectrometry analysis represents the most potent proteomics-based technology to quantify steady-state protein levels (influenced by features such as translation rates or increased degradation) and identify new candidates mediating pathological DM1 mechanisms [34].

The broad DM1 symptomatology impinges particularly on three critical body systems: skeletal and cardiac muscles and the brain. Together, these tissues comprise the focus of most omics studies done in DM1 so far, addressed specifically below (Figure 1).

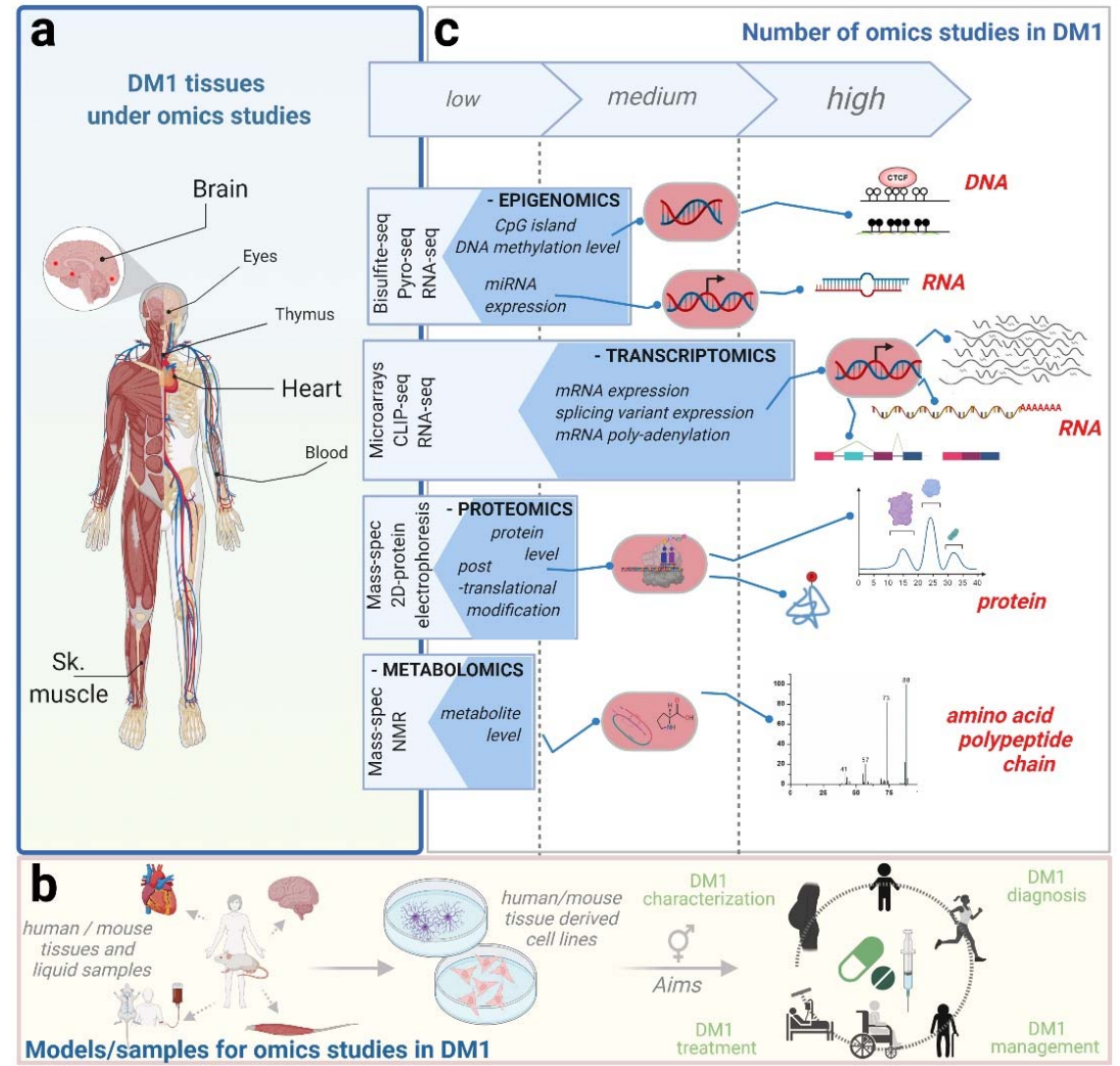

Figure 1. Omics approaches in DM1 research. Research in DM1 relies increasingly on omicsbased technologies to decipher molecular pathogeneses in key affected tissues, such as skeletal muscle, brain, and heart (a). Experimental conditions aim to elucidate certain aspects of DM1 pathology and include candidate drug testing on human primary cells, isolated directly from DM1 patient tissues: these retain the morphological and functional characteristics of their tissue of origin but display limited potential for self-renewal and differentiation. Solid omics approaches have therefore also been performed using human immortalized cell lines, as well as samples from different mouse DM1 models (b). Most frequent approaches focus on the transcriptome (RNA-Seq, CLIP-Seq, and microarrays) to build a comprehensive view of DM1 disease status at different levels of RNA metabolism (c). Furthermore, an increasing number of studies using epigenetics, proteomics, and metabolomics approaches are providing novel insights into altered pathways in DM1 (c). Altogether, these technologies provide valuable data for fundamental studies in DM1 but also on translational research characterizing drug mechanisms of action. Created with BioRender.com (accessed date 20 December 2021). 


\subsection{Omics Studies on Skeletal Muscle}

One of the most supported hypotheses in DM1 is that MBNL proteins are responsible for a large fraction of the aberrant AS patterns observed in muscle. Initial work with splicing sensitive microarray analysis found that $80 \%$ of approximately 200 alternative isoform changes observed in $\mathrm{HSA}^{\mathrm{LR}}$ mice quadriceps were reproduced in the same muscle of mice lacking functional MBNL1 proteins (MBNL1 ${ }^{\triangle \mathrm{E} 3 / \triangle \mathrm{E} 3}$ [35]), leaving $20 \%$ of isoforms affected in an MBNL1-independent but CUG-expansion-dependent manner [36,37]. A later study performed in the same model, using RNA-Seq, identified almost four times the number of misregulated AS events than were found by microarrays [38]. A complementary RNA-Seq analysis with $\mathrm{C} 2 \mathrm{C} 12$ immortalized mouse myoblast cells, silenced for MBNL1, MBNL2, or both, observed that mis-splicing severity was greater in doubly silenced cells than in each individual condition. These results indicated some redundancy in MBNL1 and 2 functions. Furthermore, a HITS-Clip experiment with several mouse tissues (brain, heart, and vastus lateralis) and $\mathrm{C} 2 \mathrm{C} 12$ cells helped map the $M B N L$ binding sites precisely. This study revealed that skeletal muscle had the most MBNL1 CLIP sites, and that these sites showed a defined pattern around alternative exons across all samples and tissues, suggesting that splicing activation or repression depends on where MBNL1 binds. Specifically, two repression peaks were found, one located right on the cassette exon and another upstream of the $3^{\prime}$-splice site, consistent with the blocking of exon enhancer elements or intronic elements (required for effective intron removal as branch site recognition by the U2AF65 protein), respectively [39]. However, additional intronic peaks were found in other regions, suggesting that repression may occur by additional mechanisms. An activation-associated CLIP peak was found 120 bases downstream of the $3^{\prime}$ end of the alternative exon. Thus, while MBNL1 binding to the alternative exon or nearby upstream sequences represses exon inclusion, binding to downstream sites enhances it [38].

A different RNA-Seq study analyzing muscle samples of a compound loss of $\mathrm{MBNL}^{\Delta \mathrm{E} 3 / \Delta \mathrm{E} 3} ; \mathrm{MBNL}^{+/-}$mouse (so-called, $\mathrm{MBNL}^{3 / 4} \mathrm{KO}$ ) showed a high correlation of splicing alterations between $\mathrm{MBNL}^{3 / 4} \mathrm{KO}, \mathrm{MBNL}^{\triangle \mathrm{E} 3 / \Delta \mathrm{E} 3}$, and $\mathrm{HSA}^{\mathrm{LR}}$, indicating a major role for MBNL sequestration in murine models of this disorder [40]. MBNL binding motif analysis was also performed, and the findings fit with the previously described patterns [38] in which binding motifs in downstream introns cause increased exon skipping, while those in upstream introns cause increased exon inclusion in DM1. Furthermore, 35 AS events, highly representative of DM1, were analyzed using a novel methodology called "targeted splice sequencing", which allows for more efficient and accurate analysis of known splicing alterations. In this study, characteristic AS events were analyzed at different developmental stages on wild type, $\mathrm{HSA}^{\mathrm{LR}}$ and $\mathrm{MBNL}^{3 / 4} \mathrm{KO}$ mice. Clear developmental transitions for most events across embryonic and adult samples were observed, suggesting that missplicing in DM1 reflects a reversion to fetal or neonatal AS patterns in muscle, as has been extensively reported in previous studies $[8,38,40]$. In another study, to further investigate alterations in developmental stages, human embryonic stem cells (hESC) were subjected to myogenic differentiation and analyzed by RNA-Seq to find evidence of differences in two developmental transitions using control and DM1 samples from hESC, myoblasts, and myotubes [41]. No core myogenic regulatory genes were altered in the hESC to myoblast transition, while a considerable number of the gene expression changes present in control myoblast to myotubes transitions were not observed in DM1 samples. Gene set enrichment analysis of these genes found an interferon-alpha response belonging to interferon type I and altered mTORC1 signaling pathways.

Despite major advances from in vitro and in vivo models, the DM1 field lacked a transcriptome dataset that would serve as a benchmark to compare to subsequent experimental analyses. To this end, www.dmseq.org (accessed date 20 December 2021) was created as part of a major RNA-Seq work that sequenced various human samples from biopsies and autopsies, including tibialis anterior samples of 44 DM1 patients and 11 unaffected controls [42]. While most of these samples were sequenced to a depth of at least 41 million reads, a subset of 50 were sequenced extremely deeply ( $>200$ million reads). 
Combining all the data, which required specific approaches for the analysis because of the different depths, provided an accurate assessment of gene expression and AS for a significant portion of the transcriptome. Notably, RNA-level data could be correlated with patients' ankle dorsiflexion strength measurements, finding a high correlation between strength and MBNL activity (defined as free MBNL protein), which was estimated by the degree of detected MBNL-dependent AS alteration (validated in a previous study using human cells) [43]. Using this value, a significant correlation was found between MBNL activity and AS of key DM1 genes such as CLCN1 and CLASP1 and various alternative last exon inclusions. Furthermore, AS alterations found in biopsies correlated significantly with known DM1 splicing biomarkers [44]. Notably, AS alterations in the quadriceps were lower than in tibialis biopsies. In the case of autopsies, a lower degree of altered AS pattern was also observed in the quadriceps when compared with other distal muscles, such as the deltoids, gastrocnemius, or soleus, providing a molecular explanation for the distal to proximal pattern of muscle weakness and wasting found in DM1 patients (milder phenotype shown in proximal muscles) [45]. The AS findings of this study replicated previous observations regarding DM1 muscle RNA metabolism, such as the abnormal inclusion of exon $7 \mathrm{a}$ or retention of intron 2 in muscle-specific chloride voltage-gated channel 1 (CLCN1) transcripts, both triggering nonsense-mediated decay resulting in a severe reduction in functional CLCN1 [46].

To evaluate the full extent of AS deregulation in DM1, another study used whole human exome microarrays to compare skeletal muscle samples of DM1 with those of other neuromuscular disorders: dystrophy type 2 (DM2), Duchenne muscular dystrophy, Becker muscular dystrophy, and Tibial muscular disease [47]. Compared to unaffected controls, 362 AS alterations were common among all diseases, and a clear tendency to gene upregulation was observed in both DM1 and DM2 compared to the other diseases. Thus, while all these disorders arise from different mutations, they share common downstream pathomechanisms in pathways related to RNA metabolism (particularly AS), growth arrest, and DNA damage-inducible genes [47].

Hundreds of genes presenting APA have been reported in DM1 muscle as part of previous RNA-Seq work [38]. A later study evaluated APA transitions in mouse embryonic fibroblasts (MEF) MBNL1 ${ }^{\triangle \mathrm{E} 3 / \triangle \mathrm{E} 3}$ and MBNL2 ${ }^{\Delta \mathrm{E} 2 / \Delta \mathrm{E} 2}$ double $\mathrm{KO}(\mathrm{DKO})$ and in MBNL null MEF (DKO/3KD) conditions, the last obtained by siRNA-induced MBNL3 silencing in the DKO background [48]. Microarrays and RNA-Seq from a library enriched in transcripts with poly(A) tails (polyA-Seq) were used to compare control vs. DKO and control vs. $\mathrm{DKO} / 3 \mathrm{KD}$. Over $4000 \mathrm{APA}$ events were found altered in the first comparison, while around a thousand more were found in the second, indicating that MBNL proteins are essential for normal MEF APA regulation. To further understand the role of MBNL3, control and DKO MEFs were analyzed with HITS-Clip, finding that most of its target sequences were intronic. Using previously available HITS-Clip data from HSA ${ }^{\mathrm{LR}}$ mice [38], an overlap of 188 common transcripts was found between MBNL1 (1351 transcripts), MBNL2 (523 transcripts), and MBNL3 (842 transcripts) targets, suggesting that MBNL proteins have both common and unique binding sites. For example, the Calm 3 transcript presents overlapping binding sites for all three MBNL proteins in two different polyadenylation sites. To clarify the biological effects of APA in DM1, HSA ${ }^{\mathrm{LR}}$ quadriceps muscle was analyzed using polyA-Seq. The findings suggest that MBNL sequestration by CUG repeats often leads to reversion to the fetal APA pattern observed in MEFs. To validate these observations, human DM1 and control vastus lateralis were analyzed by both polyA-Seq and microarray. Similar to findings in DKO/3KD MEFs, the results showed that DM1 patients have a majority $(59 \%)$ of polyadenylation sites shifted upstream. Key genes related to muscle atrophy (e.g., IGF-1, HDAC5, and mTOR) showed altered APA, suggesting that pathways known to inhibit protein synthesis and activate protein catabolism were altered [9].

Proteomics studies provide critical data about protein post-translational modifications, activity, and stability, which are crucial to elucidate the cellular pathways affected in DM1. Since these effects cannot be reliably predicted from RNA-Seq data, a combination of both 
transcriptomics and proteomics is desirable. In this regard, André et al. used myoblasts derived from DM1 patients (carrying a (CTG)2600 repeat expansion) with isogenic controls obtained after removal of the repeat tract by CRISPR/Cas9 gene editing [49]. Fifty-three proteins were differentially expressed when comparing myoblasts with and without the repeats, including two members of the metallothionein family of proteins, MT1L and MT2A, which were downregulated together with several other myogenesis-related proteins. MBNL1 protein levels were also strongly downregulated despite remaining unchanged at the mRNA level, something that the authors validated in a later study [49].

\subsection{Omics Studies in the Central Nervous System}

Central nervous system (CNS) impairments are also prominent in DM1, particularly in congenital cases, which present with intellectual disability, attention-deficit hyperactivity, and autism spectrum disorders [50]. The broad and heterogeneous cognitive and neuropsychological profiles in DM1 suggest the involvement of multiple brain areas and neuronal circuits, with defective neuron-glia interactions. Several aspects fundamental for proper brain function are likely affected and contribute to DM1 pathophysiology [26,51].

An important question addressed in the past was whether MBNL proteins are functionally affected by expanded CUG-repeats in the diseased brain, as suggested by the colocalization of DMPK RNA foci with MBNL1 and MBNL2 in brain samples [52,53]. Indeed, an RNA-Seq approach using frontal cortex and hippocampus samples from DM1, DM2, and control autopsies revealed 596 alternative exons with lower inclusion and 335 exons with higher inclusion corresponding to MBNL2 direct targets identified by HITS-Clip. Furthermore, polyA-Seq and RNA-Seq experiments were performed, identifying 2826 genes with MBNL2-regulated APA events, of which 56 were also regulated by MBNL2 at the AS level. Additionally, most APA alterations were similar to the ones described in the skeletal muscle. Altogether, the use of these three approaches confirms that MBNL2 becomes depleted from its normal RNA targets, having downstream effects on AS and APA [54].

In a complementary approach, a glial cell model of DM1 was generated using the MIO-M1 (human Muller glia) cell line expressing human DMPK gene constructs with 0 and 648 CTG repeats in an inducible doxycycline-dependent manner. Control and DM1 cell lines were analyzed using microarray technology to quantify gene expression, finding alterations in the inflammatory response. Furthermore, MBNL1- and MBNL2-dependent AS were dysregulated, and both splicing factors colocalized with CUG RNA foci, demonstrating that in MIO-M1 cells, lacking the natural DMPK genomic context, CTG expansions are sufficient to recapitulate critical molecular aspects of the disease [55].

A few recent studies have combined multiple omics approaches, including proteomics analysis, to elucidate DM1 pathological mechanisms in the brain using the DMSXL mouse model, with characteristic disease alterations in the CNS [24,25]. In a first study analyzing the frontal cortex and hippocampus of DMSXL mice, SYN1 proteins were found hyperphosphorylated in neurons by comparing the proteomic profile of the DM1 model with those of DM20 control mice expressing normal-sized DMPK transcripts [26]. Using DM20 controls for comparison allowed the proteomics data to cancel out disease intermediates originating from DMPK overexpression rather than expanded CUG RNA. SYN1 aberrant activation by phosphorylation affects synaptic vesicle transport, which was confirmed in transfected cells and post-mortem brains of DM1 patients. In another study analyzing cerebellum samples of the same mouse model, a global proteomics approach identified strongly downregulated GLT1 (a glutamate transporter) in DM1 mice and human patients [51]. GLT1 downregulation in DM1 astrocytes is caused by MBNL depletion and results in increased glutamate neurotoxicity, neuronal death, and motor incoordination. In a more recent study using the DMSXL mouse model, the authors used a multi-omics approach to investigate alterations occurring during the cell culture differentiation of four brain cell types (neurons, astrocytes, oligodendrocytes, and oligodendrocyte precursor cells), showing that astrocytes present the largest number of splicing alterations [56]. Moreover, 85 genes were observed with significantly different expressions in oligodendrocytes, of which the vast 
majority were downregulated. Next, they analyzed the shift in gene expression during the differentiation of oligodendrocytes compared to WT cell cultures. Interestingly, 80 of the 85 differentially expressed genes were altered during oligodendroglia maturation, suggesting that expanded CUG RNA primarily affects the expression of genes that are regulated during the differentiation of this cell type. In addition, the transition from an embryonic to a mature splicing pattern was also delayed in both oligodendrocytes and astrocytes, compared to the corresponding WT cells. These results suggest the presence of impaired programs of DM1 neuroglia differentiation in vitro. Functional annotation of the affected genes yielded Gene Ontology (GO) terms related to cell-membrane-dependent processes, such as cell adhesion, morphogenesis, and extracellular matrix. An exon ontology analysis of all exons abnormally spliced in astrocytes revealed enrichment for functions related to protein phosphorylation and localization, which was validated experimentally with some candidates.

A study in the frontal cortex comparing the transcriptome from 21 DM1 and 8 unaffected post-mortem, age- and sex-matched individuals found 130 exons differentially included between DM1 and controls [57]. These alterations were related to key synaptic scaffolding proteins, cytoskeletal organization components, ion channels, and neurotransmitter receptors. Analyses of cis-elements flanking dysregulated exons revealed that MBNL-bound motifs were the predominant signature, indicating that functional depletion of MBNL may be a major driver of splicing changes in the frontal cortex of DM1 patients. Results were compared to previous reports from muscle biopsies of tibialis anterior and heart muscles [42], finding a solid correlation between 25 commonly dysregulated exons, including MBNL1 exon 5, MBNL2 exon 5, and MAPT exon 3, suggesting a similar mechanism for splicing dysregulation across all tissues [57].

\subsection{Omics Studies in the Heart}

Another highly studied tissue in DM1 is the heart. Alterations specific to this organ were described in a transcriptome analysis using AS profiling microarrays performed in embryonic and adult MBNL1 ${ }^{\triangle \mathrm{E} 3 / \Delta \mathrm{E} 3}$ mice [10]. This work identified no correlation between AS and gene expression in either developmental stage but found enriched binding motifs in flanking introns of developmentally regulated exons for CELF, MBNL, and Fox RBPs. The study also measured protein levels and gene expression during embryonic development and the first two weeks after birth, observing a decrease in CELF levels and an increase in MBNL1 protein levels. Interestingly, the data showed that Fox-1 levels were negatively correlated with the depletion of CELF1 protein, while CELF2 protein decreased when Fox2 levels dropped and MBNL levels began to rise, implying a complex relationship between these RBPs. Consistent with the developmental modulation of MBNL and CELF at the protein level, 10 AS transitions correlated with this developmental shift. Collectively, these analyses identify and characterize a highly regulated AS program that supports cardiac tissue postnatal growth [10].

A similar study was performed in the hearts of Gallus gallus to identify transcripts regulated by CELF1 in the embryonic myocardium. RNA-Seq and CLIP-Seq analyses were performed for this purpose, finding that $75 \%$ of the CELF1 CLIP tags within genes mapped to intronic regions, consistent with the localization of CELF1 in the nucleus in embryonic heart muscle cells, and with its known role as a regulator of pre-mRNA AS in the heart [58]. Upon overexpressing CELF1 in mouse hearts, the authors found 234 splicing events that were altered by this RBP when compared with the previous splicing microarray data available, supporting their previous observations [38]. Of the 120 events regulated by CELF1 and MBNL1, 78 were regulated in an antagonistic fashion, suggesting that the regulated inclusion of exons tended to oppose the normal developmental transitions upon MBNL1 depletion and CELF1 induction. Interestingly, CELF1 induction in the heart was produced by only modest changes (around 15\% higher) in mRNA levels [59].

Failure of a developmental switch was also found in the heart-specific EpA960 mouse model that inducibly expresses human DMPK exon 15 containing 960 CUG repeats. A 
coordinated adult to embryonic shift was observed in the hearts of these mice upon CUG repeat RNA expression, as analyzed by microarray technology. Functional annotation of the altered genes revealed downregulation in the cardiac transcription factors $M E F 2 a$ and $M E F 2 c$, correlating with the mRNA and miRNA alterations described in this tissue [60]. In the same study, MEF2 was confirmed to be reduced in human cardiac samples. Exogenous MEF2C rescued MEF2 target miRNA and mRNA normal expression patterns in a cell model of cardiac disease. To further evaluate the role of CELF1, RNA-Seq was used to analyze DM1 heart, human fetal heart, and non-affected adult heart samples, demonstrating that RNA-Binding FOX2 (RBFOX2) was up-regulated in this DM1 tissue. Next, a doxycyclinedependent CELF1 overexpression mouse was developed to understand the relationship between this RBP and CELF1. This model showed a significant change in RBFOX2 isoforms and pro-arrhythmic phenotypes, demonstrating a link between elevated CELF1 activity and DM1-related cardiac conduction delay and arrhythmogenesis [61].

To evaluate the extent of the gene expression alterations present in DM1 hearts, an RNA-Seq approach compared AS events in heart and tibialis tissues from the autopsies of 10 DM1 patients with three unaffected individuals [42]. The findings of this study showed that exons of the cytoskeleton-related gene PDLIM3 were altered in all DM1 samples, suggesting a possible biomarker for disease progression in this tissue. A high correlation was found in the percentage of cassette exon inclusion between the heart and tibialis, suggesting that the molecular mechanisms of DM pathogenesis are conserved across both tissues. Many of these exons have been validated as MBNL-dependent targets, including MAPT, NUMA1, MBNL2, NCOR2, and LDB3. Nevertheless, several exons were tissue-specific for heart or tibialis [42].

Recently, a new mouse model has been reported, with inducible expression of human DMPK exons 11-15 carrying 960 interrupted CTG repeats in cardiomyocytes [62]. RNA-Seq from heart samples in this model revealed gene expression and AS changes in ion transport genes associated with inherited cardiac conduction diseases, including a subset of genes involved in calcium handling. Consistent with the RNA-Seq results, calcium-handling defects were identified in atrial cardiomyocytes isolated from this model, potentially contributing to the observed arrhythmogenic phenotypes [62].

\subsection{Omics Studies in Other Affected Tissues in DM1: Lens and Thymus}

Misregulated AS and alterations in RBP expression explain key phenotypes in the muscles, brain, and heart, but DM1 clinical manifestations in other tissues remain poorly understood. One example where omics approaches are providing insight is in explaining cataracts. Recent studies using microarray technology with epithelial cell lines established from the cataracts of affected DM1 and DM2 patients suggest that DMPK mRNA is highly expressed in the lens epithelia, which indicates that significant RNA toxicity may be occurring in the eyes. Gene expression alterations were also highly similar in DM1 and DM2 samples, identifying 317 significantly altered common genes and no significant alterations in DMPK transcript levels between control and DM1 or DM2 samples. A pathway analysis of the altered common genes in DM1 and DM2 identified type 1 interferon signaling pathways as a potential contributor to the advent of cataracts [63,64].

Although traditionally neglected in the DM1 field, the immune system is also known to be affected in DM1 [65]. In one study, mouse thymus development and its role in DM1 were analyzed [66]. Using RNA-Seq, the authors found MBNL1 to be highly expressed while $D M P K$ had little expression during embryogenesis, suggesting that MBNL proteins play a vital role in thymic organogenesis and thymocyte development. To further evaluate this hypothesis, publicly available RNA-Seq data from 9-week-old MBNL1 ${ }^{\Delta \mathrm{E} 3 / \Delta \mathrm{E} 3}$ mice were compared to littermate controls, finding over 1000 genes with altered expression in pathways related to the apoptotic process and cell differentiation. At the AS level, 866 alterations were found, including known MBNL1 targets CLASP1, NCOR2 exon 46, DNM2 exon 10 and 11, and transcription factor Lef1 exon 6, which has been extensively described as an important factor in thymocyte development $[67,68]$. They also used MBNL1 siRNA knock- 
down in C2C12 mouse myoblasts, which was compared to control cells by CLIP-Seq to evaluate whether the splicing defects seen in Lef1 are related to MBNL1 depletion. Results indicate that MBNL1 proteins play a role in pre-mRNA processing by regulating the AS of these critical transcription factors required for normal T-cell development [66].

\subsection{Other Omics Studies in DM1}

Given their previously known significance in human disease, DNA methylation (DNAme) and regulatory microRNA (miRNA) profiles are suitable for characterization in DM1 by means of whole-genome epigenomics experimental strategies. To date, DNAme omics studies in DM1 have focused only on CpG islands surrounding the CTG repeat [69], mainly approached using pyrosequencing omics methodology.Accumulating evidence supports that hypermethylation levels are associated with DM1 pathogenesis, with different tissues and clinical forms being affected [69]. Only one genome-wide methylation study has been performed in DM1, involving also several other trinucleotide repeat disorders. DM1 patient samples did not show a significant increase in global 5-mC compared to age- and sex-matched unaffected individuals, demonstrating the validity of targeting only specific CpG regions in DM1 [70]. Recently CpG methylation has been studied in differentiation stages, comparing hESC, myoblasts, and myotubes from control and DM1 samples. Findings suggest that congenital DM1 presents CpG methylation in the upstream site and that they increase as differentiation continues [41].

MiRNAs are ncRNA molecules that play crucial roles as epigenetic modulators, inducing post-transcriptional changes in gene expression by mRNA destabilization and/or translation repression [71]. The expression of several miRNAs has already been reported as altered in DM1, most quantified by RT-qPCR in mice or human cells (recently reviewed in [72]). Specifically based on omics experimental approaches, an RNA-Seq study was performed in patient-derived cells that analyzed the miRNA/mRNA interactions as related to the enrichment of RNA-induced silencing complex (RISC)-bound miRNAs. The study identified 24 correlations, of which 22 were first described in this work [73]. As an example of the validity of transcriptomics as a biomarker discovery tool, several miRNAs have recently been identified as DM1 biomarkers in patient hearts, skeletal muscle, and serum using RNA-Seq. A subset of miRNAs (miR-223-3p and miR-24-3p) was also found to be increased in DMSXL mice serum. Furthermore, miR-223-3p, which has been described as a neural cell degradation protector, was significantly reduced in the brain of DMSXL mice [74].

DM1 is also defined as a metabolic syndrome due to features such as dyslipidemia, insulin resistance, hypertension, and pro-inflammatory state, among other alterations consistently present in DM1 patients [75]. Recently, technologies such as proton nuclear magnetic resonance (NMR) and mass spectrometry (MS) have enabled major metabolomics studies to identify significant changes in specific metabolites in DM1. In one study, while branched-chain amino acids, acetate, and creatine levels were found elevated in the serum of patients with DM1, lysine and guanidine acetic acid levels were reduced, similar to observations in other muscular diseases [76,77]. Distinctively, glutamine levels were elevated only in the serum of DM1 patients, unlike the other muscular pathologies studied (where they were reduced), pinpointing this metabolite as a promising biomarker in clinical neurologic outcomes in conditions such as DM1 [72].

\section{Omics Studies in Candidate Drug Validations}

Given the well-defined transcriptome alterations associated with DM1, evaluating the degree of rescue and off-target effects of candidate drugs during preclinical testing by AS quantification has become customary in the field. Among the therapeutic strategies currently being explored [12,78], the repurposing of already-known small molecule drugs and RNA-based approaches has gained increasing attention for genome-wide RNA-Seq approaches, as discussed below. 
In a recent study, autophagy was found to be up-regulated in DM1 patient muscle biopsies [79] and PDIMs [80], which led to the hypothesis that repressing this catabolic pathway could improve muscle wasting. Chloroquine is a well-known autophagy blocker [81], and treatment of PDIMs with this drug improved transcriptome level alterations as measured by RNA-Seq, leading to 59\% recovery in disease-related genes in GO terms related to muscle homeostasis and function. Crucially, results were validated in the HSA ${ }^{\mathrm{LR}}$ mouse model without signs of toxicity. One of the most relevant rescue mechanisms was the increase of Muscleblind protein levels in Drosophila, HSA $^{\text {LR }}$ mice, and PDIM disease models, which prevented protein degradation [82].

An alternative approach, used by Nakamori et al., was to interrupt the interaction between toxic RNA and MBNL proteins. A drug screening searching for small molecules with these characteristics found erythromycin as a promising candidate [83]. Using HSA ${ }^{\text {LR }}$ mice versus controls, a synergistic effect was found when erythromycin was combined with furamidine. RNA-Seq analysis detected recovery of around 73\% of the AS defects observed in HSA $^{\mathrm{LR}}$ mice, a percentage nearly double the amount of that detected for furamidine or erythromycin alone, independently of dosage. Off-target effects of each treatment were evaluated by quantifying the alterations not present in control vs. HSA ${ }^{\text {LR }}$ mice but present in the $\mathrm{HSA}^{\mathrm{LR}}$ vs. HSA ${ }^{\mathrm{LR}}$-treated comparison. Off-targets were increased in the combined treatment compared to each treatment alone, but not nearly as much as when higher doses of each drug were tested alone [84].

A type 2 diabetes mellitus drug known as metformin is well ahead in the race to develop a treatment for DM1. It was tested in mesodermal precursor cells differentiated from control and patient embryonic stem cell lines at 10 and $25 \mathrm{mmol} / \mathrm{L}$, following which 63 and 1171 genes showed recovery of expression levels, respectively. Regarding AS correction, 95 and 416 exons presented a reversal above $10 \%$ at each dose. Gene enrichment analysis of the 416 transcripts identified gene sets involved in the cytoskeleton, nuclear lumen, and RNA binding. A subset of recovered AS events were validated by RT-qPCR, including DM1-related mis-splicing of INSR exon 11, TNNT2 exon 5, ATP2A1 exon 22, DMD exon 71, $D M D$ exon 78, and KIF13A exon 32, among others [85].

Since DM1 is a genetic disease, RNA-based therapies are potentially an effective strategy. An approach tested in one study aimed to degrade toxic DMPK transcripts via activation of the RNase-H machinery in the nucleus using antisense oligonucleotides (ASOs). Microarray technology was employed to evaluate alterations in genes related to apoptosis, cytotoxicity, and inflammation processes at tenfold the optimal dosage, finding no significant alterations in these processes. Promising results were also found rescuing the expression of 41 and 14 genes affected in human cell culture and DMSXL mice, respectively, advancing progress towards a clinical trial [86].

miR-218 has been reported as a natural repressor of MBNL1 and 2 [87], and it has been found overexpressed in patient-derived samples and cell models [88]. Recently, chemically engineered antisense oligonucleotides against this miRNA, also called antagomiRs, have been described as a candidate therapy for DM1 because of their potential to upregulate endogenous levels in MBNL1 and 2, thus compensating for sequestration by expanded CUG repeat RNA. Using an RNA-Seq approach with in vitro differentiated DM1 myotubes, miR-218 inhibition was found to rescue up to $34 \%$ of overall gene expression alterations. Although the analysis did not include AS, several critical genes improved their expression upon antagomiR treatment. Among others, MBNL1 and 2 levels significantly increased compared to control antagomiR-treated cells, while MBNL3, previously involved in myogenesis inhibition [15], was repressed. Furthermore, the levels of GSK3B (known to contribute to muscle atrophy [89]) and $D M P K$ were significantly downregulated upon treatment, suggesting a positive impact on known therapeutic targets of the disease.

CRISPR/Cas9 is a promising platform to potentially correct dominant genetic diseases by gene editing, showing unprecedented precision. In the DM1 field, this technology was applied to patient-derived iPSC to delete the expanded CTG repeats, after which these cells were compared to non-corrected ones by RNA-Seq $[90,91]$. The authors found 
less than $1 \%$ (fewer than 200 genes) with significant differences in gene expression (reads aligned to genes), while there were over a thousand significant differences in transcript expression (reads aligned to gene isoforms). The 99 most significant altered transcripts were selected and functionally annotated, revealing altered pathways related to cardiac development, maturation, and function, including the expression of gated ion channels. Interestingly, 7 out of 99 top-affected transcripts were involved in AS, as splicing regulators or spliceosomal complex components. AS was also investigated, revealing a difference in the splicing pattern of genes associated with cardiac function, cellular signaling, and DM1 disease markers such as NUMA1, MBNL2, and LDB3. Interestingly, disease-causing DMPK transcripts also presented AS.

\section{Conclusions and Future Perspectives}

This review has provided an overview of the most relevant key studies to date using omics data to elucidate DM1 molecular pathogenesis (Table 1), putting into perspective the specific alterations discovered in each tissue, the methodologies used to identify them, and the contribution of each study to the development of effective DM1 treatment.

Table 1. Current omics data available from DM1 studies.

\begin{tabular}{|c|c|c|c|c|c|c|}
\hline Technique & Type & Sample & Species & Objective & Reference & Cite \\
\hline CLIP-Seq & $\begin{array}{l}\text { Illumina Genome } \\
\text { Analyzer II }\end{array}$ & Embryonic fibroblasts & Human, mouse & $\begin{array}{c}\text { Alternative } \\
\text { polyadenylation }\end{array}$ & GSE60487 & [9] \\
\hline $\begin{array}{l}\text { 2D WB and nano } \\
\text { LC-MS/MS }\end{array}$ & $\begin{array}{l}\text { MALDI-TOF Voyager } \\
\text {-DE-STR and Q-TOF MS }\end{array}$ & $\begin{array}{l}\text { Frontal cortex and } \\
\text { hippocampus }\end{array}$ & Mouse & $\begin{array}{l}\text { Proteome and } \\
\text { phosphoproteome } \\
\text { analysis }\end{array}$ & Not provided & [26] \\
\hline Microarray & $\begin{array}{c}\text { ares_ucsc_mouse_59198_ } \\
\text { affyMouseA }\end{array}$ & $\begin{array}{l}\text { Skeletal muscle } \\
\text { biopsies }\end{array}$ & Mouse & Alternative splicing & GSE17986 & [36] \\
\hline RNA-Seq & Illumina HiSeq 2000 & $\begin{array}{l}\text { Brain, heart, skeletal } \\
\text { muscle, and cell } \\
\text { cultures }\end{array}$ & Mouse & Transcriptome analysis & GSE39911 & [38] \\
\hline CLIP-Seq & $\begin{array}{l}\text { Illumina Genome } \\
\text { Analyzer II }\end{array}$ & $\begin{array}{l}\text { Brain, heart, skeletal } \\
\text { muscle, and cell } \\
\text { cultures }\end{array}$ & Mouse & RBP binding sites & GSE39911 & [38] \\
\hline RNA-Seq & Illumina HiSeq 2500 & Quadriceps & Mouse & Transcriptome analysis & PRJNA625451 & [40] \\
\hline RNA-Seq & Illumina NextSeq 500 & $\begin{array}{c}\text { Embryonic stem cells, } \\
\text { myoblast, myotubes }\end{array}$ & Human & Transcriptome analysis & GSE160916 & [41] \\
\hline RNA-Seq & Illumina HiSeq 2000 & $\begin{array}{l}\text { Skeletal muscle and } \\
\text { heart biopsies and } \\
\text { autopsies }\end{array}$ & Human & Transcriptome analysis & GSE86356 & [42] \\
\hline Microarray & $\begin{array}{l}\text { Human Exon } 1.0 \mathrm{ST} \\
\text { array }\end{array}$ & $\begin{array}{l}\text { Skeletal muscle } \\
\text { biopsies }\end{array}$ & Human & Alternative splicing & GSE48828 & [47] \\
\hline LC-MS/MS & $\begin{array}{c}\text { EASY-nLC 1200-rbitrap } \\
\text { Tribid MS }\end{array}$ & Myoblasts & Human & $\begin{array}{c}\text { Global proteome } \\
\text { analysis }\end{array}$ & PXD016056 & [49] \\
\hline $\begin{array}{c}\text { iTraq Nano-LC- } \\
\text { MS/MS }\end{array}$ & $\begin{array}{c}\text { Ultimate } 3000 \text { RSLC } \\
\text { LTQ-Orbitrap Velos MS }\end{array}$ & Cerebellum & Mouse & $\begin{array}{l}\text { Global proteome } \\
\text { analysis }\end{array}$ & Not provided & [51] \\
\hline CLIP-Seq & $\begin{array}{l}\text { Illumina Genome } \\
\text { Analyzer II }\end{array}$ & Brain & Human, mouse & $\begin{array}{l}\text { RBP binding sites, } \\
\text { alternative } \\
\text { polyadenylation }\end{array}$ & GSE68890 & [54] \\
\hline Microarray & Clariom D Arrays & Cell culture & Human & Transcriptome analysis & GSE164057 & [55] \\
\hline RNA-Seq & Illumina HiSeq 2500 & $\begin{array}{c}\text { Astrocytes, } \\
\text { oligodendrocytes, and } \\
\text { neurons }\end{array}$ & Mouse & Transcriptome analysis & GSE162093 & [56] \\
\hline $\begin{array}{l}\text { 2D WB and nano } \\
\text { LC-MS/MS }\end{array}$ & Nano RSLC-Q & Astrocytes & Mouse & $\begin{array}{c}\text { Phosphoproteome } \\
\text { analysis }\end{array}$ & PXD025011 & [56] \\
\hline RNA-Seq & Illumina NextSeq 500 & $\begin{array}{l}\text { Frontal cortex } \\
\text { biopsies }\end{array}$ & Human & Transcriptome analysis & GSE157428 & [57] \\
\hline CLIP-Seq & $\begin{array}{l}\text { Illumina Genome } \\
\text { Analyzer II }\end{array}$ & Heart & Chicken & RBP binding sites & GSE67360 & [58] \\
\hline RNA-Seq & Illumina HiSeq 2000 & Muscle, heart & Mouse & Transcriptome analysis & GSE61893 & [59] \\
\hline CLIP-Seq & $\begin{array}{l}\text { Illumina Genome } \\
\text { Analyzer II }\end{array}$ & Muscle, heart & Mouse & RBP binding sites & GSE61893 & [59] \\
\hline
\end{tabular}


Table 1. Cont.

\begin{tabular}{|c|c|c|c|c|c|c|}
\hline Technique & Type & Sample & Species & Objective & Reference & Cite \\
\hline Microarray & $\begin{array}{l}\text { Illumina MouseWG-6 } \\
\text { v2.0 expression } \\
\text { beadchip }\end{array}$ & Heart & Mouse & Transcriptome analysis & GSE48991 & [60] \\
\hline RNA-Seq & Illumina HiSeq 4000 & Heart & Mouse & Transcriptome analysis & GSE126771 & [61] \\
\hline RNA-Seq & Illumina NovaSeq 6000 & Heart & Mouse & Transcriptome analysis & GSE164825 & [62] \\
\hline Microarray & $\begin{array}{c}\text { HumanHT-12 v3 } \\
\text { Expression BeadChip }\end{array}$ & Lens epithelial & Human & Transcriptome analysis & E-MEXP-3365 & [64] \\
\hline RNA-Seq & $\begin{array}{l}\text { Illumina HiSeq 2500, } \\
\text { Illumina NextSeq } 500\end{array}$ & Thymus & Human, mouse & Transcriptome analysis & GSE138691 & [66] \\
\hline RNA-Seq & Illumina HiSeq 2500 & Biceps brachii & Human & $\begin{array}{l}\text { miRNA/mRNA } \\
\text { interactions }\end{array}$ & GSE108592 & [73] \\
\hline RNA-Seq & Illumina NextSeq 500 & $\begin{array}{c}\text { Blood } \\
\text { Muscles, heart, and } \\
\text { brain }\end{array}$ & $\begin{array}{l}\text { Human, } \\
\text { mouse }\end{array}$ & miRNA analysis & PRJEB46413 & {$[74]$} \\
\hline RNA-Seq & Illumina NextSeq 550 & Cell culture & Human & Transcriptome analysis & GSE128844 & [82] \\
\hline RNA-Seq & Illumina NextSeq 500 & Quadriceps & Mouse & Transcriptome analysis & PRJNA555349 & [84] \\
\hline RNA-Seq & Illumina HiSeq 2000 & Cell culture & Human & Transcriptome analysis & GSE138789 & [85] \\
\hline
\end{tabular}

As known major players in DM1 pathology, MBNL and CELF proteins are a primary focus of analysis in multiple omics studies. Mounting omics evidence suggests critical roles for these RBPs as competitors or co-regulating factors in key AS and APA events. The ubiquitous nature of the DMPK gene, together with the toxicity of expanded CUG repeats over both RBPs, may partly explain the multisystemic nature of DM1. In addition, the key role in splicing regulation of these proteins most probably accounts for the high quantity of AS alterations found across DM1 tissues.

Future perspectives in DM1 research advocate implementing current state-of-the-art technologies such as single-cell and third-generation sequencing. Single-cell analysis is currently used as a potent tool to explore omics changes in tissues composed of a complex mixture of cell types. This could be particularly important in the DM1 field since the most affected tissues are composed of a variety of cells with very specialized functions. Furthermore, expanded CTG microsatellites show somatic instability [92], presenting genetic mosaicism in each tissue. The cells usually carry a different number of CTG repeats in their genome, thus contributing to an intrinsic degree of variability. Therefore, the findings of most of the studies described herein can only be discussed in the context of pooled information coming from these mixtures of cells, which in many cases might obscure important findings and limit the scope of the study. Studying omics from cells differentiated in vitro can partially overcome this problem but does not provide the same context and clues as to the conditions present in vivo, constituting a fundamental limitation of this approach. To this end, single-cell analysis of DM1 tissue could provide important new information to elucidate how the disease affects the function of each cell type in the original context.

The unprecedented accuracy in evaluating the RNA composition of DM1 samples has provided strong support for the toxic RNA hypothesis, by pinpointing all AS and APA changes in the disease and the regulatory factors involved. Moreover, omics approaches now provide global metrics to compare the efficacy of candidate therapies. Nevertheless, current sequencing technologies suffer from limitations: repeat expansions or structural variants have proven very challenging to sequence, and, despite certain progress, there is still room for improvement. Third-generation sequencing, such as Oxford Nanopore Technologies (ONT) or Pacific Bioscience single-molecule, real-time technologies (SMRT), can bypass these limitations by generating long reads covering an average of $20 \mathrm{Kbp}$ and $30 \mathrm{Kbp}$, respectively, with the current record being $2.3 \mathrm{Mbp}$ of a single continuous read from ONT [93-96]. For DM1, this could open up interesting new areas of research for an accurate description of RNA isoform composition, instead of exon use as the current state-of-the-art, with major implications for diagnostic, structure, and drug discovery applications. As was seen recently in the evaluation of $\mathrm{CpG}$ islands methylation [41]. 
Another field with great potential is data mining of already available datasets. For example, taking advantage of the extreme depths of RNA-Seq data in dmseq.org [42], one study analyzed the misexpression of circular RNAs (circRNAs: highly stable, lowly expressed RNAs coming from protein-coding transcripts). Although their origins are still under-researched, several RBPs are known to participate in their biogenesis [97]. The average expression of specific circRNAs, such as circCAMSAP1, circHIPK3, circNFATC3, and circZKSCAN1, is increased in DM1 with no similar change in the linear transcripts from which they derive. Interestingly, a negative correlation between circRNA level in tibialis anterior tissue and ankle dorsiflexion force was found, suggesting a relationship between circRNA and disease severity [98].

Finally, breakthrough advances in artificial intelligence (AI) are enabling accurate protein structure predictions [99], which in the context of DM1 research could help anticipate the effects of specific AS alterations at the proteome level and integrate multiomics approaches into our understanding of the disease. Taken together, this technology could support researchers in their goal to enhance knowledge of the intrinsic behavior of DM1-affected proteins, through which new types of structure-specific treatments can be developed to correct molecular damage.

Author Contributions: J.E.-E.: conceptualization, methodology, investigation, writing-original draft preparation. A.G.-B.: investigation, writing-review and editing. A.L.-C.: investigation, visualization, writing-review and editing. R.A.: conceptualization, writing-review and editing, supervision. All authors have read and agreed to the published version of the manuscript.

Funding: The authors received research funds by PROMETEO/2020/081 from the Generalitat Valenciana and HR17-00268 (TATAMI project) from the "la Caixa" Banking Foundation to R.A., J.E.E was the recipient of a Santiago Grisolía award, Grisoliap2018/098, from the Conselleria for Education, Research, Culture, and Sport.

Acknowledgments: Jorge Espinosa-Espinosa would like to thank the insights provided by the Translational Genomics Group of the Universidad de Valencia and F. Gutierrez during the writing of this paper.

Conflicts of Interest: The authors declare no conflict of interest.

\section{References}

1. Theadom, A.; Rodrigues, M.; Roxburgh, R.; Balalla, S.; Higgins, C.; Bhattacharjee, R.; Jones, K.; Krishnamurthi, R.; Feigin, V. Prevalence of muscular dystrophies: A systematic literature review. Neuroepidemiology 2014, 43, 259-268. [CrossRef] [PubMed]

2. Johnson, N.E.; Butterfield, R.J.; Mayne, K.; Newcomb, T.; Imburgia, C.; Dunn, D.; Duval, B.; Feldkamp, M.L.; Weiss, R.B. Population-Based Prevalence of Myotonic Dystrophy Type 1 Using Genetic Analysis of Statewide Blood Screening Program. Neurology 2021, 96, e1045-e1053. [CrossRef] [PubMed]

3. Day, J.W.; Ranum, L.P.W. Genetics and molecular pathogenesis of the myotonic dystrophies. Curr. Neurol. Neurosci. Rep. 2005, 5, 55-59. [CrossRef] [PubMed]

4. Musova, Z.; Mazanec, R.; Krepelova, A.; Ehler, E.; Vales, J.; Jaklova, R.; Prochazka, T.; Koukal, P.; Marikova, T.; Kraus, J.; et al. Highly unstable sequence interruptions of the CTG repeat in the myotonic dystrophy gene. Am. J. Med. Genet. 2009, 149A, 1365-1374. [CrossRef]

5. $\quad$ Ebralidze, A.; Wang, Y.; Petkova, V.; Ebralidse, K.; Junghans, R.P. RNA leaching of transcription factors disrupts transcription in myotonic dystrophy. Science 2004, 303, 383-387. [CrossRef]

6. Huichalaf, C.; Sakai, K.; Jin, B.; Jones, K.; Wang, G.-L.; Schoser, B.; Schneider-Gold, C.; Sarkar, P.; Pereira-Smith, O.M.; Timchenko, N.; et al. Expansion of CUG RNA repeats causes stress and inhibition of translation in myotonic dystrophy 1 (DM1) cells. FASEB J. 2010, 24, 3706-3719. [CrossRef]

7. Rau, F.; Freyermuth, F.; Fugier, C.; Villemin, J.-P.; Fischer, M.-C.; Jost, B.; Dembele, D.; Gourdon, G.; Nicole, A.; Duboc, D.; et al. Misregulation of miR-1 processing is associated with heart defects in myotonic dystrophy. Nat. Struct. Mol. Biol. 2011, 18, 840-845. [CrossRef]

8. López-Martínez, A.; Soblechero-Martín, P.; de-la-Puente-Ovejero, L.; Nogales-Gadea, G.; Arechavala-Gomeza, V. An Overview of Alternative Splicing Defects Implicated in Myotonic Dystrophy Type I. Genes 2020, 11, 1109. [CrossRef]

9. Batra, R.; Charizanis, K.; Manchanda, M.; Mohan, A.; Li, M.; Finn, D.J.; Goodwin, M.; Zhang, C.; Sobczak, K.; Thornton, C.A.; et al. Loss of MBNL Leads to Disruption of Developmentally Regulated Alternative Polyadenylation in RNA-Mediated Disease. Mol. Cell 2014, 56, 311-322. [CrossRef] 
10. Kalsotra, A.; Xiao, X.; Ward, A.J.; Castle, J.C.; Johnson, J.M.; Burge, C.B.; Cooper, T.A. A postnatal switch of CELF and MBNL proteins reprograms alternative splicing in the developing heart. Proc. Natl. Acad. Sci. USA 2008, 105, 20333-20338. [CrossRef]

11. Ashizawa, T.; Gagnon, C.; Groh, W.J.; Gutmann, L.; Johnson, N.E.; Meola, G.; Moxley, R.; Pandya, S.; Rogers, M.T.; Simpson, E.; et al. Consensus-based care recommendations for adults with myotonic dystrophy type 1. Neurol. Clin. Pract. 2018, 8, 507-520. [CrossRef] [PubMed]

12. Pascual-Gilabert, M.; López-Castel, A.; Artero, R. Myotonic dystrophy type 1 drug development: A pipeline toward the market. Drug Discov. Today 2021, 26, 1765-1772. [CrossRef] [PubMed]

13. Fardaei, M.; Rogers, M.T.; Thorpe, H.M.; Larkin, K.; Hamshere, M.G.; Harper, P.S.; Brook, J.D. Three proteins, MBNL, MBLL and MBXL, co-localize in vivo with nuclear foci of expanded-repeat transcripts in DM1 and DM2 cells. Hum. Mol. Genet. 2002, 11, 805-814. [CrossRef] [PubMed]

14. Lee, K.-S.; Cao, Y.; Witwicka, H.E.; Tom, S.; Tapscott, S.J.; Wang, E.H. RNA-binding protein Muscleblind-like 3 (MBNL3) disrupts myocyte enhancer factor 2 (Mef2) \{beta\}-exon splicing. J. Biol. Chem. 2010, 285, 33779-33787. [CrossRef]

15. Konieczny, P.; Stepniak-Konieczna, E.; Sobczak, K. MBNL proteins and their target RNAs, interaction and splicing regulation. Nucleic Acids Res. 2014, 42, 10873-10887. [CrossRef] [PubMed]

16. Choi, J.; Dixon, D.M.; Dansithong, W.; Abdallah, W.F.; Roos, K.P.; Jordan, M.C.; Trac, B.; Lee, H.S.; Comai, L.; Reddy, S. Muscleblind-like 3 deficit results in a spectrum of age-associated pathologies observed in myotonic dystrophy. Sci. Rep. 2016, 6, 30999. [CrossRef] [PubMed]

17. Dasgupta, T.; Ladd, A.N. The importance of CELF control: Molecular and biological roles of the CUG-BP, Elav-like family of RNA-binding proteins: Importance of CELF control. WIREs RNA 2012, 3, 104-121. [CrossRef] [PubMed]

18. Nasiri-Aghdam, M.; Garcia-Garduño, T.C.; Jave-Suárez, L.F. CELF Family Proteins in Cancer: Highlights on the RNA-Binding Protein/Noncoding RNA Regulatory Axis. Int. J. Mol. Sci. 2021, 22, 11056. [CrossRef]

19. Greenberg, D.S.; Soreq, H. Alternative Splicing. In Brenner's Encyclopedia of Genetics, 2nd ed.; Maloy, S., Hughes, K., Eds.; Academic Press: San Diego, CA, USA, 2013; pp. 97-98. ISBN 978-0-08-096156-9.

20. Pan, Q.; Shai, O.; Lee, L.J.; Frey, B.J.; Blencowe, B.J. Deep surveying of alternative splicing complexity in the human transcriptome by high-throughput sequencing. Nat. Genet. 2008, 40, 1413-1415. [CrossRef]

21. Yeh, H.-S.; Yong, J. Alternative Polyadenylation of mRNAs: $3^{\prime}$-Untranslated Region Matters in Gene Expression. Mol. Cells 2016, 39, 281-285. [CrossRef]

22. Proudfoot, N.J. Ending the message: Poly(A) signals then and now. Genes Dev. 2011, 25, 1770-1782. [CrossRef]

23. Mankodi, A.; Logigian, E.; Callahan, L.; McClain, C.; White, R.; Henderson, D.; Krym, M.; Thornton, C.A. Myotonic dystrophy in transgenic mice expressing an expanded CUG repeat. Science 2000, 289, 1769-1773. [CrossRef] [PubMed]

24. Gomes-Pereira, M.; Foiry, L.; Nicole, A.; Huguet, A.; Junien, C.; Munnich, A.; Gourdon, G. CTG Trinucleotide Repeat “Big Jumps": Large Expansions, Small Mice. PLoS Genet. 2007, 3, e52. [CrossRef] [PubMed]

25. Huguet, A.; Medja, F.; Nicole, A.; Vignaud, A.; Guiraud-Dogan, C.; Ferry, A.; Decostre, V.; Hogrel, J.-Y.; Metzger, F.; Hoeflich, A.; et al. Molecular, Physiological, and Motor Performance Defects in DMSXL Mice Carrying >1000 CTG Repeats from the Human DM1 Locus. PLoS Genet. 2012, 8, e1003043. [CrossRef] [PubMed]

26. Hernández-Hernández, O.; Guiraud-Dogan, C.; Sicot, G.; Huguet, A.; Luilier, S.; Steidl, E.; Saenger, S.; Marciniak, E.; Obriot, H.; Chevarin, C.; et al. Myotonic dystrophy CTG expansion affects synaptic vesicle proteins, neurotransmission and mouse behaviour. Brain 2013, 136, 957-970. [CrossRef] [PubMed]

27. Arandel, L.; Polay Espinoza, M.; Matloka, M.; Bazinet, A.; De Dea Diniz, D.; Naouar, N.; Rau, F.; Jollet, A.; Edom-Vovard, F.; Mamchaoui, K.; et al. Immortalized human myotonic dystrophy muscle cell lines to assess therapeutic compounds. Dis. Model Mech. 2017, 10, 487-497. [CrossRef] [PubMed]

28. Goodwin, S.; McPherson, J.D.; McCombie, W.R. Coming of age: Ten years of next-generation sequencing technologies. Nat. Rev. Genet. 2016, 17, 333-351. [CrossRef]

29. Peña-Bautista, C.; Baquero, M.; Vento, M.; Cháfer-Pericás, C. Omics-based Biomarkers for the Early Alzheimer Disease Diagnosis and Reliable Therapeutic Targets Development. Curr. Neuropharmacol. 2019, 17, 630-647. [CrossRef]

30. Heo, Y.J.; Hwa, C.; Lee, G.-H.; Park, J.-M.; An, J.-Y. Integrative Multi-Omics Approaches in Cancer Research: From Biological Networks to Clinical Subtypes. Mol. Cells 2021, 44, 433-443. [CrossRef]

31. Morello, G.; Salomone, S.; D'Agata, V.; Conforti, F.L.; Cavallaro, S. From Multi-Omics Approaches to Precision Medicine in Amyotrophic Lateral Sclerosis. Front. Neurosci. 2020, 14, 1151. [CrossRef]

32. Bonder, M.J.; Smail, C.; Gloudemans, M.J.; Frésard, L.; Jakubosky, D.; D'Antonio, M.; Li, X.; Ferraro, N.M.; Carcamo-Orive, I.; Mirauta, B.; et al. Identification of rare and common regulatory variants in pluripotent cells using population-scale transcriptomics. Nat. Genet. 2021, 53, 313-321. [CrossRef] [PubMed]

33. Morozova, O.; Hirst, M.; Marra, M.A. Applications of New Sequencing Technologies for Transcriptome Analysis. Annu. Rev. Genom. Hum. Genet. 2009, 10, 135-151. [CrossRef] [PubMed]

34. Aslam, B.; Basit, M.; Nisar, M.A.; Khurshid, M.; Rasool, M.H. Proteomics: Technologies and Their Applications. J. Chromatogr. Sci. 2017, 55, 182-196. [CrossRef] [PubMed]

35. Kanadia, R.N.; Johnstone, K.A.; Mankodi, A.; Lungu, C.; Thornton, C.A.; Esson, D.; Timmers, A.M.; Hauswirth, W.W.; Swanson, M.S. A muscleblind knockout model for myotonic dystrophy. Science 2003, 302, 1978-1980. [CrossRef] 
36. Du, H.; Cline, M.S.; Osborne, R.J.; Tuttle, D.L.; Clark, T.A.; Donohue, J.P.; Hall, M.P.; Shiue, L.; Swanson, M.S.; Thornton, C.A.; et al. Aberrant alternative splicing and extracellular matrix gene expression in mouse models of myotonic dystrophy. Nat. Struct. Mol. Biol. 2010, 17, 187-193. [CrossRef]

37. Llorian, M.; Smith, C.W. Decoding muscle alternative splicing. Curr. Opin. Genet. Dev. 2011, 21, 380-387. [CrossRef]

38. Wang, E.T.; Cody, N.A.L.; Jog, S.; Biancolella, M.; Wang, T.T.; Treacy, D.J.; Luo, S.; Schroth, G.P.; Housman, D.E.; Reddy, S.; et al. Transcriptome-wide Regulation of Pre-mRNA Splicing and mRNA Localization by Muscleblind Proteins. Cell 2012, 150, 710-724. [CrossRef]

39. Warf, M.B.; Nakamori, M.; Matthys, C.M.; Thornton, C.A.; Berglund, J.A. Pentamidine reverses the splicing defects associated with myotonic dystrophy. Proc. Natl. Acad. Sci. USA 2009, 106, 18551-18556. [CrossRef]

40. Tanner, M.K.; Tang, Z.; Thornton, C.A. Targeted splice sequencing reveals RNA toxicity and therapeutic response in myotonic dystrophy. Nucleic Acids Res. 2021, 49, 2240-2254. [CrossRef]

41. Franck, S.; Couvreu De Deckersberg, E.; Bubenik, J.L.; Markouli, C.; Barbé, L.; Allemeersch, J.; Hilven, P.; Duqué, G.; Swanson, M.S.; Gheldof, A.; et al. Myotonic dystrophy type 1 embryonic stem cells show decreased myogenic potential, increased CpG methylation at the DMPK locus and RNA mis-splicing. Biol. Open 2022, 11, bio058978. [CrossRef]

42. Wang, E.T.; Treacy, D.; Eichinger, K.; Struck, A.; Estabrook, J.; Olafson, H.; Wang, T.T.; Bhatt, K.; Westbrook, T.; Sedehizadeh, S.; et al. Transcriptome alterations in myotonic dystrophy skeletal muscle and heart. Hum. Mol. Genet. 2019, 28, 1312-1321. [CrossRef] [PubMed]

43. Wagner, S.D.; Struck, A.J.; Gupta, R.; Farnsworth, D.R.; Mahady, A.E.; Eichinger, K.; Thornton, C.A.; Wang, E.T.; Berglund, J.A. Dose-Dependent Regulation of Alternative Splicing by MBNL Proteins Reveals Biomarkers for Myotonic Dystrophy. PLoS Genet. 2016, 12, e1006316. [CrossRef] [PubMed]

44. Nakamori, M.; Sobczak, K.; Puwanant, A.; Welle, S.; Eichinger, K.; Pandya, S.; Dekdebrun, J.; Heatwole, C.R.; McDermott, M.P.; Chen, T.; et al. Splicing biomarkers of disease severity in myotonic dystrophy. Ann. Neurol. 2013, 74, 862-872. [CrossRef] [PubMed]

45. Thomas, J.D.; Oliveira, R.; Sznajder, Ł.J.; Swanson, M.S. Myotonic Dystrophy and Developmental Regulation of RNA Processing Compr. Physiol. 2018, 8, 509-553. [CrossRef] [PubMed]

46. Chau, A.; Kalsotra, A. Developmental insights into the pathology of and therapeutic strategies for DM1: Back to the basics: DM1 disease mechanisms and therapeutics. Dev. Dyn. 2015, 244, 377-390. [CrossRef]

47. Bachinski, L.L.; Baggerly, K.A.; Neubauer, V.L.; Nixon, T.J.; Raheem, O.; Sirito, M.; Unruh, A.K.; Zhang, J.; Nagarajan, L.; Timchenko, L.T.; et al. Most expression and splicing changes in myotonic dystrophy type 1 and type 2 skeletal muscle are shared with other muscular dystrophies. Neuromuscul. Disord. 2014, 24, 227-240. [CrossRef]

48. Lee, K.-Y.; Li, M.; Manchanda, M.; Batra, R.; Charizanis, K.; Mohan, A.; Warren, S.A.; Chamberlain, C.M.; Finn, D.; Hong, H.; et al Compound loss of muscleblind-like function in myotonic dystrophy. EMBO Mol. Med. 2013, 5, 1887-1900. [CrossRef]

49. André, L.M.; van Cruchten, R.T.P.; Willemse, M.; Bezstarosti, K.; Demmers, J.A.A.; van Agtmaal, E.L.; Wansink, D.G.; Wieringa, B. Recovery in the Myogenic Program of Congenital Myotonic Dystrophy Myoblasts after Excision of the Expanded (CTG)n Repeat. Int. J. Mol. Sci. 2019, 20, 5685. [CrossRef]

50. Meola, G.; Sansone, V. Cerebral involvement in myotonic dystrophies. Muscle Nerve 2007, 36, 294-306. [CrossRef]

51. Sicot, G.; Servais, L.; Dinca, D.M.; Leroy, A.; Prigogine, C.; Medja, F.; Braz, S.O.; Huguet-Lachon, A.; Chhuon, C.; Nicole, A.; et al. Downregulation of the Glial GLT1 Glutamate Transporter and Purkinje Cell Dysfunction in a Mouse Model of Myotonic Dystrophy. Cell Rep. 2017, 19, 2718-2729. [CrossRef]

52. Jiang, H.; Mankodi, A.; Swanson, M.S.; Moxley, R.T.; Thornton, C.A. Myotonic dystrophy type 1 is associated with nuclear foci of mutant RNA, sequestration of muscleblind proteins and deregulated alternative splicing in neurons. Hum. Mol. Genet. 2004, 13, 3079-3088. [CrossRef] [PubMed]

53. Gourdon, G.; Meola, G. Myotonic Dystrophies: State of the Art of New Therapeutic Developments for the CNS. Front Cell Neurosci. 2017, 11, 101. [CrossRef] [PubMed]

54. Goodwin, M.; Mohan, A.; Batra, R.; Lee, K.-Y.; Charizanis, K.; Gómez, F.J.F.; Eddarkaoui, S.; Sergeant, N.; Buée, L.; Kimura, T.; et al. MBNL Sequestration by Toxic RNAs and RNA Mis-Processing in the Myotonic Dystrophy Brain. Cell Rep. 2015, 12, 1159-1168. [CrossRef] [PubMed]

55. Azotla-Vilchis, C.N.; Sanchez-Celis, D.; Agonizantes-Juárez, L.E.; Suárez-Sánchez, R.; Hernández-Hernández, J.M.; Peña, J.; Vázquez-Santillán, K.; Leyva-García, N.; Ortega, A.; Maldonado, V.; et al. Transcriptome Analysis Reveals Altered Inflammatory Pathway in an Inducible Glial Cell Model of Myotonic Dystrophy Type 1. Biomolecules 2021, 11, 159. [CrossRef]

56. González-Barriga, A.; Lallemant, L.; Dincã, D.M.; Braz, S.O.; Polvèche, H.; Magneron, P.; Pionneau, C.; Huguet-Lachon, A.; Claude, J.-B.; Chhuon, C.; et al. Integrative Cell Type-Specific Multi-Omics Approaches Reveal Impaired Programs of Glial Cell Differentiation in Mouse Culture Models of DM1. Front. Cell. Neurosci. 2021, 15, 662035. [CrossRef]

57. Otero, B.A.; Poukalov, K.; Hildebrandt, R.P.; Thornton, C.A.; Jinnai, K.; Fujimura, H.; Kimura, T.; Hagerman, K.A.; Sampson, J.B.; Day, J.W.; et al. Transcriptome alterations in myotonic dystrophy frontal cortex. Cell Rep. 2021, 34, 108634. [CrossRef]

58. Blech-Hermoni, Y.; Dasgupta, T.; Coram, R.J.; Ladd, A.N. Identification of Targets of CUG-BP, Elav-Like Family Member 1 (CELF1) Regulation in Embryonic Heart Muscle. PLoS ONE 2016, 11, e0149061. [CrossRef]

59. Wang, E.T.; Ward, A.J.; Cherone, J.M.; Giudice, J.; Wang, T.T.; Treacy, D.J.; Lambert, N.J.; Freese, P.; Saxena, T.; Cooper, T.A.; et al. Antagonistic regulation of mRNA expression and splicing by CELF and MBNL proteins. Genome Res. 2015, 25, 858-871. [CrossRef] 
60. Kalsotra, A.; Singh, R.K.; Gurha, P.; Ward, A.J.; Creighton, C.J.; Cooper, T.A. The Mef2 transcription network is disrupted in myotonic dystrophy heart tissue dramatically altering miRNA and mRNA expression. Cell Rep. 2014, 6, 336-345. [CrossRef]

61. Misra, C.; Bangru, S.; Lin, F.; Lam, K.; Koenig, S.N.; Lubbers, E.R.; Hedhli, J.; Murphy, N.P.; Parker, D.J.; Dobrucki, L.W.; et al. Aberrant Expression of a Non-muscle RBFOX2 Isoform Triggers Cardiac Conduction Defects in Myotonic Dystrophy. Dev. Cell 2020, 52, 748-763.e6. [CrossRef]

62. Rao, A.N.; Campbell, H.M.; Guan, X.; Word, T.A.; Wehrens, X.H.T.; Xia, Z.; Cooper, T.A. Reversible cardiac disease features in an inducible CUG repeat RNA-expressing mouse model of myotonic dystrophy. JCI Insight 2021, 6, e143465. [CrossRef] [PubMed]

63. Klesert, T.R.; Cho, D.H.; Clark, J.I.; Maylie, J.; Adelman, J.; Snider, L.; Yuen, E.C.; Soriano, P.; Tapscott, S.J. Mice deficient in Six5 develop cataracts: Implications for myotonic dystrophy. Nat. Genet. 2000, 25, 105-109. [CrossRef] [PubMed]

64. Rhodes, J.D.; Lott, M.C.; Russell, S.L.; Moulton, V.; Sanderson, J.; Wormstone, I.M.; Broadway, D.C. Activation of the innate immune response and interferon signalling in myotonic dystrophy type 1 and type 2 cataracts. Hum. Mol. Genet. 2012, 21, 852-862. [CrossRef] [PubMed]

65. Kanadia, R.N.; Urbinati, C.R.; Crusselle, V.J.; Luo, D.; Lee, Y.-J.; Harrison, J.K.; Oh, S.P.; Swanson, M.S. Developmental expression of mouse muscleblind genes Mbnl1, Mbnl2 and Mbnl3. Gene Expr. Patterns 2003, 3, 459-462. [CrossRef]

66. Sznajder, Ł.J.; Scotti, M.M.; Shin, J.; Taylor, K.; Ivankovic, F.; Nutter, C.A.; Aslam, F.N.; Subramony, S.H.; Ranum, L.P.W.; Swanson, M.S. Loss of MBNL1 induces RNA misprocessing in the thymus and peripheral blood. Nat. Commun. 2020, 11, 2022. [CrossRef]

67. Kernfeld, E.M.; Genga, R.M.J.; Neherin, K.; Magaletta, M.E.; Xu, P.; Maehr, R. A Single-Cell Transcriptomic Atlas of Thymus Organogenesis Resolves Cell Types and Developmental Maturation. Immunity 2018, 48, 1258-1270.e6. [CrossRef]

68. Weber, B.N.; Chi, A.W.-S.; Chavez, A.; Yashiro-Ohtani, Y.; Yang, Q.; Shestova, O.; Bhandoola, A. A critical role for TCF-1 in T-lineage specification and differentiation. Nature 2011, 476, 63-68. [CrossRef] [PubMed]

69. Visconti, V.V.; Centofanti, F.; Fittipaldi, S.; Macrì, E.; Novelli, G.; Botta, A. Epigenetics of Myotonic Dystrophies: A Minireview. Int. J. Mol. Sci. 2021, 22, 12594. [CrossRef]

70. Hamzeiy, H.; Savaş, D.; Tunca, C.; Şen, N.E.; Gündoğdu Eken, A.; Şahbaz, I.; Calini, D.; Tiloca, C.; Ticozzi, N.; Ratti, A.; et al. Elevated Global DNA Methylation Is Not Exclusive to Amyotrophic Lateral Sclerosis and Is Also Observed in Spinocerebellar Ataxia Types 1 and 2. NDD 2018, 18, 38-48. [CrossRef]

71. Bartel, D.P. MicroRNAs: Genomics, Biogenesis, Mechanism, and Function. Cell 2004, 116, 281-297. [CrossRef]

72. López Castel, A.; Overby, S.J.; Artero, R. MicroRNA-Based Therapeutic Perspectives in Myotonic Dystrophy. Int. J. Mol. Sci. 2019, 20, 5600. [CrossRef] [PubMed]

73. Cappella, M.; Perfetti, A.; Cardinali, B.; Garcia-Manteiga, J.M.; Carrara, M.; Provenzano, C.; Fuschi, P.; Cardani, R.; Renna, L.V.; Meola, G.; et al. High-throughput analysis of the RNA-induced silencing complex in myotonic dystrophy type 1 patients identifies the dysregulation of miR-29c and its target ASB2. Cell Death Dis. 2018, 9, 729. [CrossRef] [PubMed]

74. Koutalianos, D.; Koutsoulidou, A.; Mytidou, C.; Kakouri, A.C.; Oulas, A.; Tomazou, M.; Kyriakides, T.C.; Prokopi, M.; Kapnisis, K.; Nikolenko, N.; et al. miR-223-3p and miR-24-3p as novel serum-based biomarkers for myotonic dystrophy type 1. Mol. Ther. -Methods Clin. Dev. 2021, 23, 169-183. [CrossRef] [PubMed]

75. Mateus, T.; Martins, F.; Nunes, A.; Herdeiro, M.T.; Rebelo, S. Metabolic Alterations in Myotonic Dystrophy Type 1 and Their Correlation with Lipin. Int. J. Env. Res. Public Health 2021, 18, 1794. [CrossRef] [PubMed]

76. Srivastava, N.K.; Annarao, S.; Sinha, N. Metabolic status of patients with muscular dystrophy in early phase of the disease: In vitro, high resolution NMR spectroscopy based metabolomics analysis of serum. Life Sci. 2016, 151, 122-129. [CrossRef] [PubMed]

77. Spitali, P.; Hettne, K.; Tsonaka, R.; Sabir, E.; Seyer, A.; Hemerik, J.B.A.; Goeman, J.J.; Picillo, E.; Ergoli, M.; Politano, L.; et al Cross-sectional serum metabolomic study of multiple forms of muscular dystrophy. J. Cell Mol. Med. 2018, 22, 2442-2448. [CrossRef]

78. Overby, S.J.; Cerro-Herreros, E.; Llamusi, B.; Artero, R. RNA-mediated therapies in myotonic dystrophy. Drug Discov. Today 2018, 23, 2013-2022. [CrossRef]

79. Bargiela, A.; Cerro-Herreros, E.; Fernandez-Costa, J.M.; Vilchez, J.J.; Llamusi, B.; Artero, R. Increased autophagy and apoptosis contribute to muscle atrophy in a myotonic dystrophy type 1 Drosophila model. Dis. Model Mech. 2015, 8, 679-690. [CrossRef]

80. Sabater-Arcis, M.; Bargiela, A.; Furling, D.; Artero, R. miR-7 Restores Phenotypes in Myotonic Dystrophy Muscle Cells by Repressing Hyperactivated Autophagy. Mol. Ther. Nucleic Acids 2020, 19, 278-292. [CrossRef]

81. Mauthe, M.; Orhon, I.; Rocchi, C.; Zhou, X.; Luhr, M.; Hijlkema, K.-J.; Coppes, R.P.; Engedal, N.; Mari, M.; Reggiori, F. Chloroquine inhibits autophagic flux by decreasing autophagosome-lysosome fusion. Autophagy 2018, 14, 1435-1455. [CrossRef]

82. Bargiela, A.; Sabater-Arcis, M.; Espinosa-Espinosa, J.; Zulaica, M.; de Munain, A.L.; Artero, R. Increased Muscleblind levels by chloroquine treatment improve myotonic dystrophy type 1 phenotypes in in vitro and in vivo models. Proc. Natl. Acad. Sci. USA 2019, 116, 25203-25213. [CrossRef] [PubMed]

83. Nakamori, M.; Taylor, K.; Mochizuki, H.; Sobczak, K.; Takahashi, M.P. Oral administration of erythromycin decreases RNA toxicity in myotonic dystrophy. Ann. Clin. Transl. Neurol. 2015, 3, 42-54. [CrossRef]

84. Jenquin, J.R.; Yang, H.; Huigens III, R.W.; Nakamori, M.; Berglund, J.A. Combination Treatment of Erythromycin and Furamidine Provides Additive and Synergistic Rescue of Mis-splicing in Myotonic Dystrophy Type 1 Models. ACS Pharmacol. Transl. Sci. 2019, 2, 247-263. [CrossRef] [PubMed] 
85. Laustriat, D.; Gide, J.; Barrault, L.; Chautard, E.; Benoit, C.; Auboeuf, D.; Boland, A.; Battail, C.; Artiguenave, F.; Deleuze, J.-F.; et al. In Vitro and In Vivo Modulation of Alternative Splicing by the Biguanide Metformin. Mol. Ther. Nucleic Acids 2015, 4, e262. [CrossRef] [PubMed]

86. Jauvin, D.; Chrétien, J.; Pandey, S.K.; Martineau, L.; Revillod, L.; Bassez, G.; Lachon, A.; McLeod, A.R.; Gourdon, G.; Wheeler, T.M.; et al. Targeting DMPK with Antisense Oligonucleotide Improves Muscle Strength in Myotonic Dystrophy Type 1 Mice. Mol. Ther. Nucleic Acids 2017, 7, 465-474. [CrossRef] [PubMed]

87. Cerro-Herreros, E.; Sabater-Arcis, M.; Fernandez-Costa, J.M.; Moreno, N.; Perez-Alonso, M.; Llamusi, B.; Artero, R. miR-23b and miR-218 silencing increase Muscleblind-like expression and alleviate myotonic dystrophy phenotypes in mammalian models. Nat. Commun. 2018, 9, 2482. [CrossRef]

88. Cerro-Herreros, E.; González-Martínez, I.; Moreno, N.; Espinosa-Espinosa, J.; Fernández-Costa, J.M.; Colom-Rodrigo, A.; Overby, S.J.; Seoane-Miraz, D.; Poyatos-García, J.; Vilchez, J.J.; et al. Preclinical characterization of antagomiR-218 as a potential treatment for myotonic dystrophy. Mol. Ther.-Nucleic Acids 2021, 26, 174-191. [CrossRef]

89. Wei, C.; Stock, L.; Valanejad, L.; Zalewski, Z.A.; Karns, R.; Puymirat, J.; Nelson, D.; Witte, D.; Woodgett, J.; Timchenko, N.A.; et al. Correction of GSK3 $\beta$ at young age prevents muscle pathology in mice with myotonic dystrophy type 1. FASEB J. 2018, 32, 2073-2085. [CrossRef]

90. Dastidar, S.; Ardui, S.; Singh, K.; Majumdar, D.; Nair, N.; Fu, Y.; Reyon, D.; Samara, E.; Gerli, M.F.M.; Klein, A.F.; et al. Efficient CRISPR/Cas9-mediated editing of trinucleotide repeat expansion in myotonic dystrophy patient-derived iPS and myogenic cells. Nucleic Acids Res. 2018, 46, 8275-8298. [CrossRef]

91. Dastidar, S.; Majumdar, D.; Tipanee, J.; Singh, K.; Klein, A.F.; Furling, D.; Chuah, M.K.; VandenDriessche, T. Comprehensive transcriptome-wide analysis of spliceopathy correction of myotonic dystrophy using CRISPR-Cas9 in iPSCs-derived cardiomyocytes. Mol. Ther. 2021, 30, 75-91. [CrossRef]

92. Morales, F.; Couto, J.M.; Higham, C.F.; Hogg, G.; Cuenca, P.; Braida, C.; Wilson, R.H.; Adam, B.; del Valle, G.; Brian, R.; et al. Somatic instability of the expanded CTG triplet repeat in myotonic dystrophy type 1 is a heritable quantitative trait and modifier of disease severity. Hum. Mol. Genet. 2012, 21, 3558-3567. [CrossRef] [PubMed]

93. Merker, J.D.; Wenger, A.M.; Sneddon, T.; Grove, M.; Zappala, Z.; Fresard, L.; Waggott, D.; Utiramerur, S.; Hou, Y.; Smith, K.S.; et al Long-read genome sequencing identifies causal structural variation in a Mendelian disease. Genet. Med. 2018, 20, 159-163. [CrossRef] [PubMed]

94. Flower, M.; Lomeikaite, V.; Ciosi, M.; Cumming, S.; Morales, F.; Lo, K.; Hensman Moss, D.; Jones, L.; Holmans, P.; Monckton, D.G.; et al. MSH3 modifies somatic instability and disease severity in Huntington's and myotonic dystrophy type 1. Brain 2019, 142, 1876-1886. [CrossRef] [PubMed]

95. Mitsuhashi, S.; Matsumoto, N. Long-read sequencing for rare human genetic diseases. J. Hum. Genet. 2020, 65, 11-19. [CrossRef] [PubMed]

96. Chintalaphani, S.R.; Pineda, S.S.; Deveson, I.W.; Kumar, K.R. An update on the neurological short tandem repeat expansion disorders and the emergence of long-read sequencing diagnostics. Acta Neuropathol. Commun. 2021, 9, 98. [CrossRef] [PubMed]

97. Conn, S.J.; Pillman, K.A.; Toubia, J.; Conn, V.M.; Salmanidis, M.; Phillips, C.A.; Roslan, S.; Schreiber, A.W.; Gregory, P.A.; Goodall, G.J. The RNA Binding Protein Quaking Regulates Formation of circRNAs. Cell 2015, 160, 1125-1134. [CrossRef]

98. Czubak, K.; Taylor, K.; Piasecka, A.; Sobczak, K.; Kozlowska, K.; Philips, A.; Sedehizadeh, S.; Brook, J.D.; Wojciechowska, M.; Kozlowski, P. Global Increase in Circular RNA Levels in Myotonic Dystrophy. Front. Genet. 2019, 10, 649. [CrossRef]

99. Jumper, J.; Evans, R.; Pritzel, A.; Green, T.; Figurnov, M.; Ronneberger, O.; Tunyasuvunakool, K.; Bates, R.; Žídek, A.; Potapenko, A.; et al. Highly accurate protein structure prediction with AlphaFold. Nature 2021, 596, 583-589. [CrossRef] 